Jurnal

Kardiologi Indonesia

J Kardiol Indones. 2013;34:60-5

ISSN $0126 / 3773$

Forum Pencitraan Jantung

\title{
Interpretasi Hasil Pemeriksaan MRI Kardiak pada Penyakit Jantung Koroner
}

\author{
Sony Hilal Wicaksono, Fachmi Ahmad Muslim, Vienna Rossimarina
}

S eorang pasien dapat didiagnosis penyakit jantung koroner (PJK) melalui empat cara: kematian jantung mendadak, sindrom koroner akut, angina pektoris stabil paska revaskularisasi, dan hasil diagnostik noninvasif (Computed
Tomography scan/CT scan koroner, Single Photon Emission Computed Tomography Myocardial Perfusion Imaging/SPECT MPI nuklir atau Magnetic Resonance Imaging/MRI $)^{1}$. Pemeriksaan noninvasif memegang peranan penting, yaitu sebagai satu-satunya cara

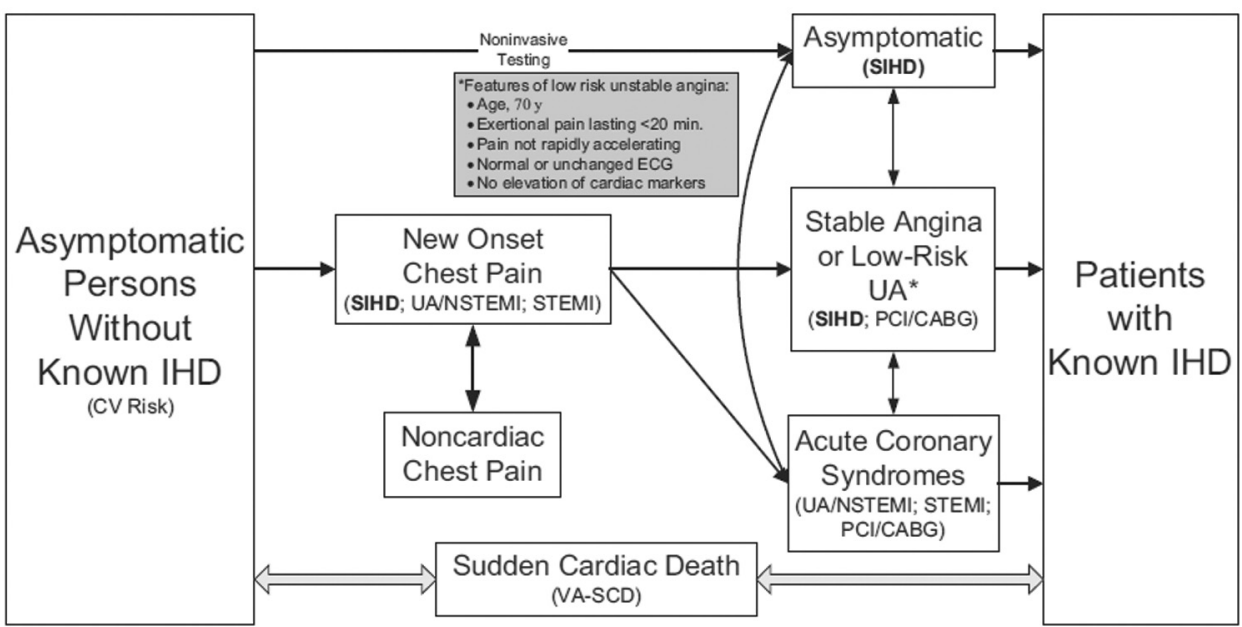

Gambar 1. Algoritma Diagnosis PJK

Dikutip dari kepustakaan ${ }^{1}$

\section{Alamat korespondensi:}

dr. Soni Hilal Wicaksono, SpJP. Departemen Kardiologi dan Kedokteran Vaskuler FKUI dan Pusat Jantung Nasional Harapan, Kita, JI S Parman Kav 87 Jakarta I I420, E-mail: sonyhilalw@gmail.com mendiagnosis PJK asimtomatik. Oleh sebab itu, pemahaman mengenai interpretasi hasil pemeriksaan noninvasif seperti CT scan koroner, SPECT MPI nuklir atau MRI kardiak dimasukkan dalam kompetensi dasar 
program pendidikan spesialis jantung dan pembuluh darah menurut Kolegium PERKI.

Penggunaan MRI sebagai salah satu modalitas diagnostik PJK, akhir-akhir ini sangat berkembang. MRI memiliki beberapa keuntungan dibandingkan dengan modalitas lain, yaitu tidak menggunakan radiasi, menghasilkan gambar dengan resolusi temporal dan spasial yang akurat, dapat mengevaluasi anatomi dan fungsi dari kardiak, serta lapang tomografi yang tidak terbatas. ${ }^{2}$ Hasil MRI selain menjadi bukti diagnostik, dapat juga membantu menentukan tatalaksana dan memperlihatkan prognosis pasien. Berikut ini perbandingan MRI kardiak dengan modalitas noninvasif lainnya.

Hasil pemeriksaan MRI kardiak terdiri atas gambar dan sine yang diambil dari beberapa metode sekuens. Tiap-tiap sekuens memberikan informasi yang khas. Sekuens pemeriksaan MRI yang diperlukan untuk mendiagnosis PJK adalah a) T1 darkblood aksial dan koronal, b) Steady StateFree Precision (SSFP)fase rest dan stress, c) T2-weightedSTIR, d) Stress First-Pass Perfusion dan RestFirst-Pass Perfusion, e) Early Gadolinium Enhancement(EGE) dan Late Gadolinium Enhancement (LGE), seperti yang ditunjukkan pada gambar 2.

\section{TI darkblood aksial dan koronal}

MRI kardiak menggunakan sine, yaitu gambar bergerak, dengan bright blood dan dark blood fast spin-echo(FSE) untuk menilai morfologi dan struktur kardiak. T-1 weighted dark blood FSE, yaitu gambar yang memperlihatkan darah berwarna hitam sementara lemak berwarna putih, digunakan untuk mengevaluasi morfologi ruang jantung, sruktur vaskular, dan perikardium. 2,5,6 Pemeriksaan ini dapat menilai anatomi dan morfologi lapis demi lapis dari organ jantung.

Tabel 1. Kelebihan dan kekurangan modalitas diagnostik noninvasif ${ }^{3}$

\begin{tabular}{lccccc}
\hline & Anatomi & Fungsi Stress & Perfusi Stress & Oksigenasi & Prognosis \\
\hline SPECT & - & + & ++ & + & +++ \\
MRI kardiak & ++ & +++ & ++ & ++ & + \\
Ekhokardiografi & ++ & +++ & $+/-$ & - & +++ \\
Angiografi CT & +++ & - & $+/-$ & - & + \\
\hline
\end{tabular}

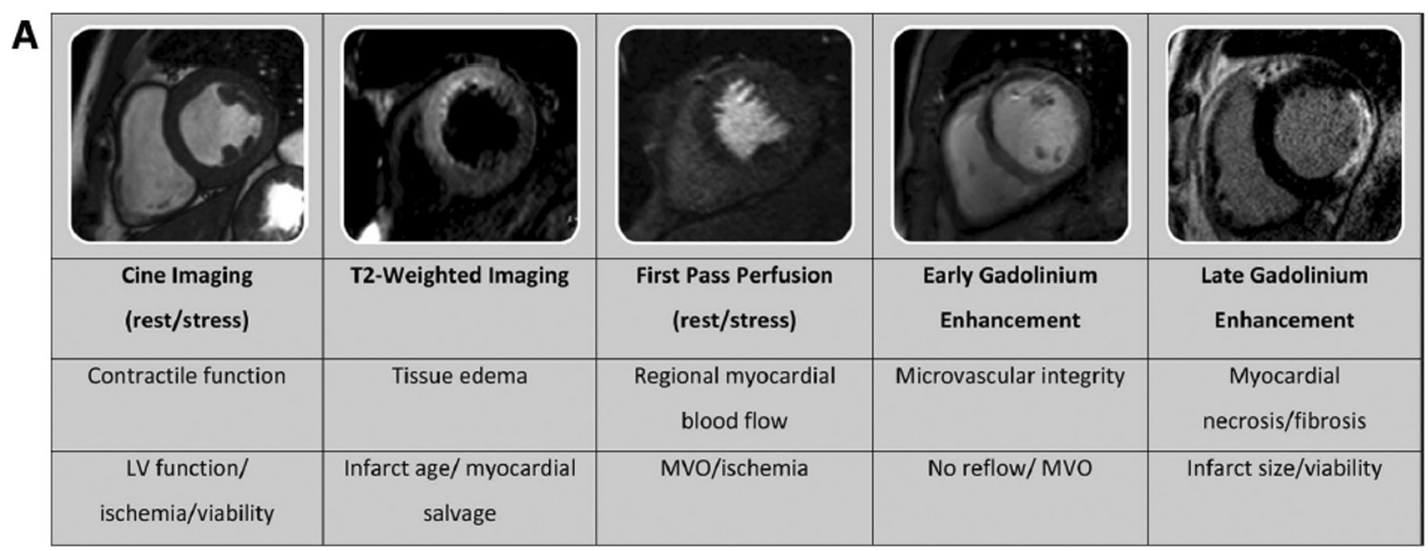

B

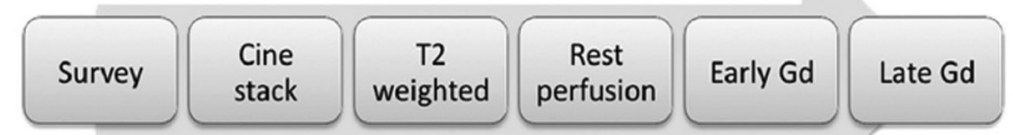

Gambar 2. Sekuens Pemeriksaan MRI untuk Mendiagnosis PJK.

Dikutip dari kepustakaan ${ }^{4}$ 
Jurnal Kardiologi Indonesia

\section{Steady State Free Precision (SSFP) fase rest dan stress}

Pemeriksaan SSFP menghasilkan sine untuk menilai morfologi dan fungsi miokard, katup dan aorta. SSFP menggunakan prinsip bright blood imaging. Gambar bright blood memperlihatkan darah dengan intensitas sinyal terang.Pada proses ini, beberapagambar diambil secara berurutan untuk memperlihatkan dinamika pergerakan kardiak. ${ }^{6}$ Gambar yang dihasilkan serupa dengan yang didapat dari echo yaitu 4 chamber view, 2 chamber view, LVOT view dan short axis view dari potongan apikal hingga basal. SSFP juga dapat menilai fungsi ventrikel kiri dan kanan berdasarkan data sine yang disusun berdasarkan 10-12 potongan short axis ventrikel kiri secara berurutan. ${ }^{4}$ Analisa segmental dapat dilakukan dengan lebih mudah dan akurat untuk tiap segmen melalui potongan gambar ini.

Pemeriksaan SSFP fase stress dilakukan dengan menggunakan dobutamin.Pergerakan dinding pada fase stress dibandingkan dengan faserest untuk menemukan defek pergerakan dinding yang diinduksi oleh stres (inducible wall motion defect) untuk mendeteksi iskemia dan memprediksi perbaikan fungsi miokard paska revaskularisasi bila ditemukan peningkatan kontraktilitas pada segmen yang sebelumnya akinetik atau hipokinetik berat.Setelah infark miokard akut, MRI kardiak dengan dobutamin dosis rendah dapat digunakan untuk memprediksi viabilitas dan penyembuhan fungsional, sementara MRI dengan dobutamin dosis tinggi memiliki akurasi diagnostik yang tinggi untuk mengidentifikasi abnormalitas pergerakan dinding ventrikel kiri akibat stenosis aliran koroner. ${ }^{4}$

\section{T2-weighted STIR}

Edema miokard merupakan salah satu bentukjejas miokard yang dihubungkan dengan inflamasi. Peningkatan kadar air pada inflamasi akan meningkatkan sinyal pada T2weighted image sehingga akan tervisualisasi sebagai sinyal terang. Oleh sebab itu, sekuens ini dapat digunakan untuk menilai inflamasi di miokard. Keuntungan terbesar dari teknik ini adalah dapat membedakan infark kronik dengan yang akut, yaitu temuan hiperintens pada sekuens ini mengindikasikan inflamasi akut masih terjadi. Edema miokard pada fase akut infark miokard pada T2-weighted imaging didefinisikan sebagai "myocardium at risk". Proporsi miokard yang dapat diselamatkan paska infark miokard akut dapat diukur sebagai luas area "myocardium at risk", dengan cara membandingkan ukuran edema pada T2-weighted dengan ukuran LGE. 2,4,7

\section{Stress First Pass Perfusion dan Rest First Pass Perfusion}

Pemeriksaan ini digunakan untuk menilai perfusi koroner. Autoregulasi koroner memiliki mekanisme khusus untuk mempertahankan aliran darah ke miokard dalam keadaan istirahat, walaupun terdapat obstruksi pada arteri koroner epikardial. Sementara dalam keadaan stress, perfusi miokard tidak adekuat apabila terdapat stenosis arteri koroner epikardial. ${ }^{8}$ Prinsip ini digunakan pada pemeriksaan first pass perfusion test. Pasien diberi kondisi stres melalui pemberian vasodilator seperti adenosin dan dipiridamol, selanjutnya kontras Gadolinium diberikan dan dilihat perfusinya ke dalam miokard.

PJK didiagnosis apabilaterdapat defek perfusi pada saat stress tetapi hilang saat rest. Temuan ini disebut inducible ischemia.Apabila defek perfusi pada saat stress menetap pada saat rest, maka dapat disimpulkan adanya disfungsi mikrovaskular atau obstruksi mikrovaskular. Oleh sebab itu, MRI dapat pula digunakan untuk mengevaluasi perbaikan fungsional kardiak setelah intervensi koroner perkutan. Obstruksi mikrovaskular memiliki nilai prognostik tersendiri, yaitu prognosis yang lebih buruk apabila ditemukan paska intervensi koroner perkutan. Keberadaan dan luas obstruksi mikrovaskular sebanding dengan durasi iskemia sebelum intervensi koroner. ${ }^{8}$ Dengan demikian, hasil pemeriksaan first pass perfussion test dapat digunakan sebagai indikator dini beratnya infark. ${ }^{9}$

\section{Early Gadolinium Enhancement (EGE) dan Late Gadolinium Enhancement (LGE)}

Setelah jejas iskemia akut, distribusi gadolinium di ekstrasel meningkat akibat disintegrasi sarkolema dan pengeluaran ke intravaskular yang abnormal. Perbedaan yang dihasilkan antara miokardium yang normal dengan yang mengalami jejas dapat diperlihatkan oleh T1-sensitive inversion recovery. Pengambilan gambar dalam beberapa menit setelah pemberian kontras (EGE) merupakan metode untuk memperlihatkan obstruksi mikro vaskulardan trombus, karena kontras sulit untuk masuk ke area infark dan menghasilkan sinyal rendah pada gambar T1. 
Pada infark miokard kronik, jaringan fibrotik meningkatkan volume distribusi kontras. Jaringan yang mengalami jejas akut dan infark kronik tanpa obstruksi mikrovaskular akan menahan kontras lebih lama dan akan tampak lebih terang, terutama dalam 10-20 menit setelah pemberian kontras. Pemeriksaan ini disebut LGE, dan telah menjadi standar penilaian viabilitas miokard. LGE digunakan untuk melihat

\section{T1 darkblood aksial dan koronal}

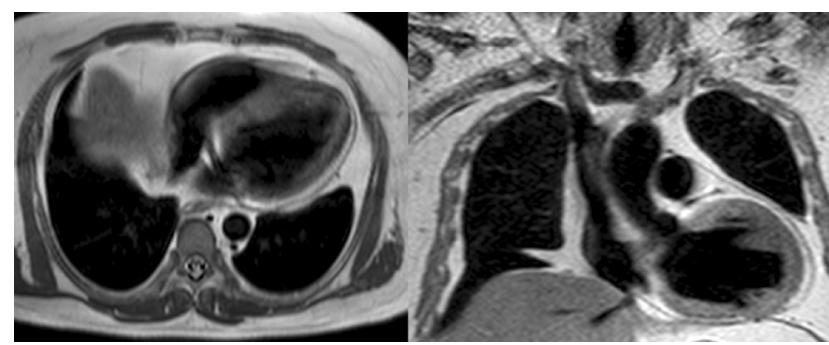

Gambar 3.Tampak gambaran atomi kardiak pada potongan aksial (a) dan koronal (b)

\section{Steady State Free Precision (SSFP)}
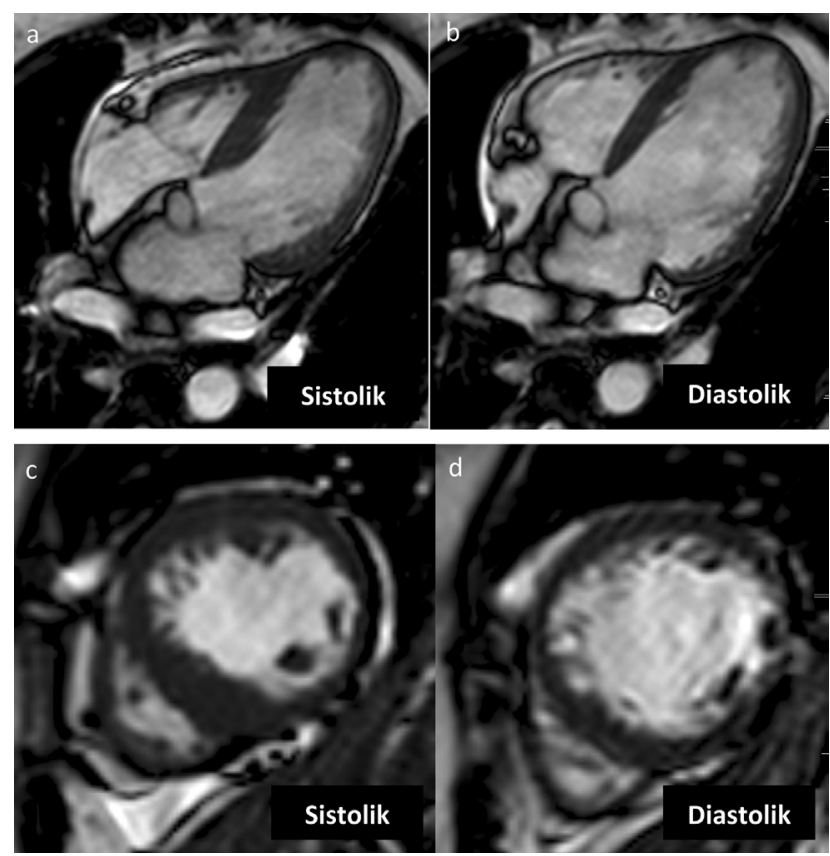

Gambar 4. Pada potongan horizontal long axis(a dan b), tampak akin etik di apexdan pada dinding lateral dari apikal hingga mid. Pada potongan short axis(c dan d) tampak akinetik di mid inferior, mid inferolateral dan hipokinetik berat di mid anterior, mid anteroseptal pada pasien inferoposterior infark miokard akut dengan ST elevasi (IMA-ST). scar atau jaringan parut pada miokard sehingga dapat dinilai viabilitas dan kemungkinan perbaikan fungsi paskarevaskularisasi. Viabilitas dinilai berdasarkantransmuralitas scar, yaitu dikatakan viable bila transmuralitasnya kurang dari $50 \% .^{10}$

\section{Ringkasan}

Pemeriksaan noninvasif, termasuk MRI kardiak, memegang peranan penting dalam mendiagnosis PJK asimtomatik. Beberapa sekuens pengambilan gambar

\section{T2-weighted STIR}

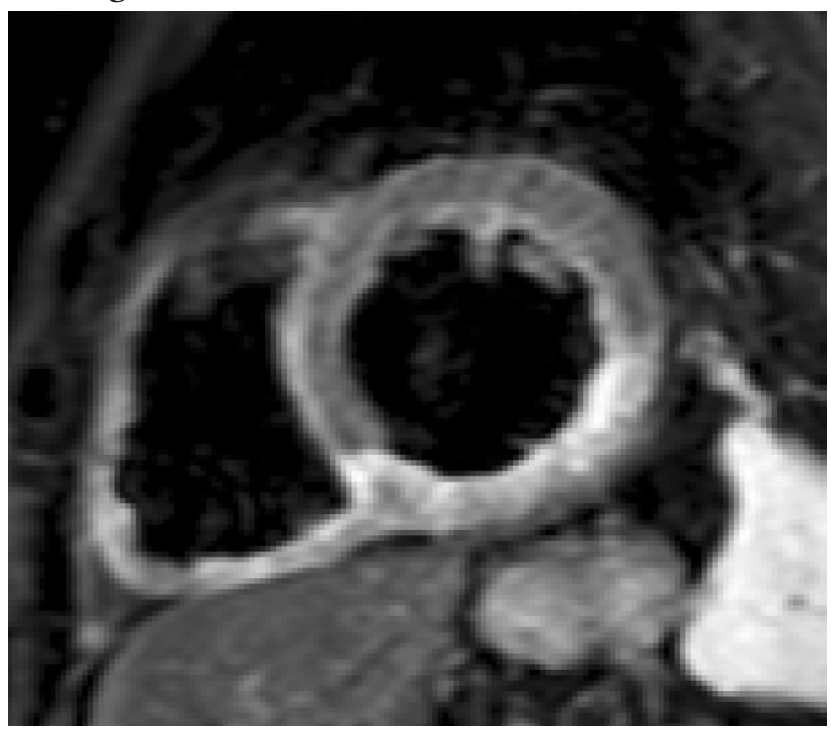

Gambar 5.Tampak hiperintens di mid inferior dan ventrikel kanan inferoposterior pada pasien inferioposterior IMA-ST

\section{First-Pass Perfusion}

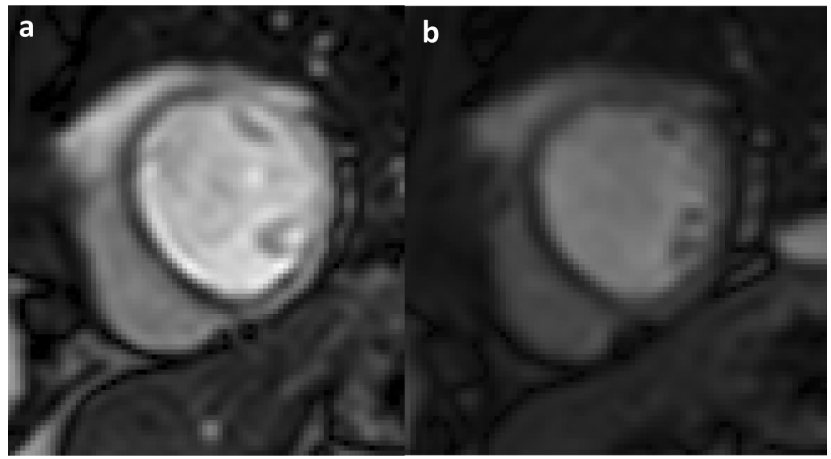

Gambar 6 a. Stress perfusion defect di mid anteroseptal, inferoseptaldan inferior. b. Rest perfusion defect di mid anteroseptal. 


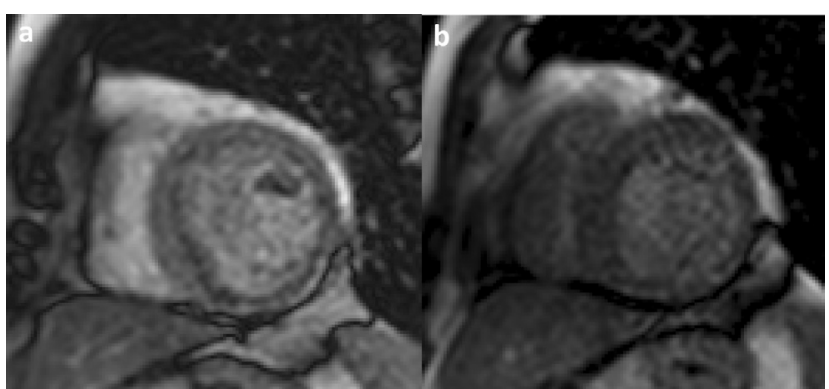

Gambar 7. Stress inducible ischemia digambarkan dengan adanya stress perfusion defect di mid inferolateral, inferior dan inferoseptal (gambar a) tanparest perfussion defect (gambar b).

\section{Early Gadolinium Enhancement (EGE)}

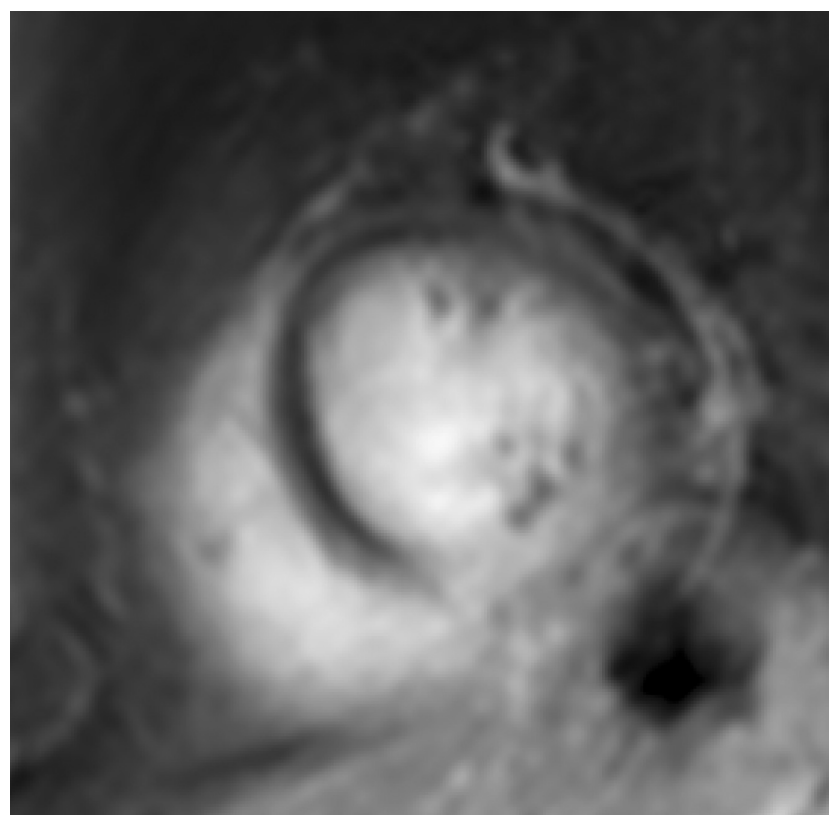

Gambar 8. Mild hipoperfusi (EGE) di midanteroseptal.

digunakan untuk mengevaluasi morfologi dan fungsi jantung secara detail, memperlihatkan stress inducible ischemia, dan menghitung luas jaringan fibrosis. Hasil pemeriksaan MRI kardiak memberikan banyak informasi yang bermanfaat untuk mendiagnosis PJK, menentukan strategi tatalaksananya dan memperkirakan prognosis pasien.

\section{Daftar Pustaka}

1. Fihn SD, Gardin JM, Abrams J, Berra K, Blankenship JC, Dallas AP, et al. 2012 ACCF/AHA/ACP/AATS/PCNA/SCAI/STS

\section{Late Gadolinium Enhancement (LGE)}

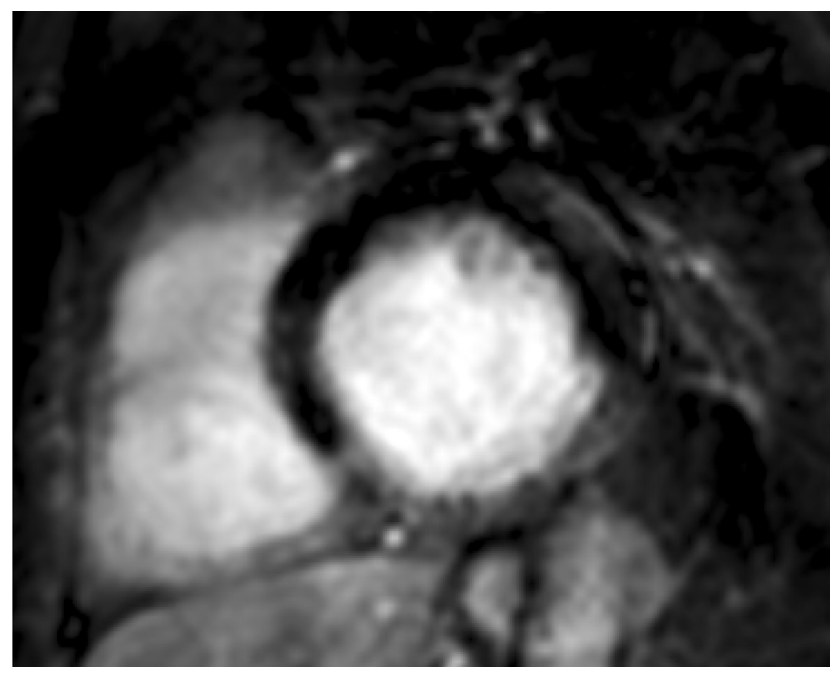

Gambar 9. Hiperintens (LGE) di mid inferior hingga inferolateral dengan transmuralitas $51-75 \%$ pada pasien inferoposterior IMA-ST.

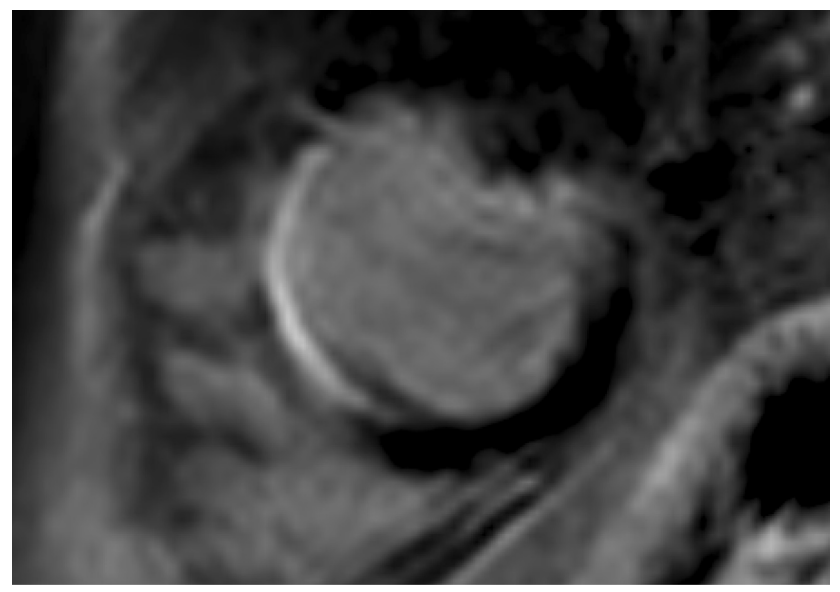

Gambar 10. Hiperenintens (LGE) pada mid anteroseptal hingga mid anterior dengantransmuralitas antara 75$100 \%$.

Guideline for the Diagnosis and Management of Patients With Stable Ischemic Heart Disease: Executive Summary: A Report of the American College of Cardiology Foundation/American Heart Association Task Force on Practice Guidelines, and the American College of Physicians, American Association for Thoracic Surgery, Preventive Cardiovascular Nurses Association, Society for Cardiovascular Angiography and Interventions, and Society of Thoracic Surgeons. Circulation. 2012; 126(25): 

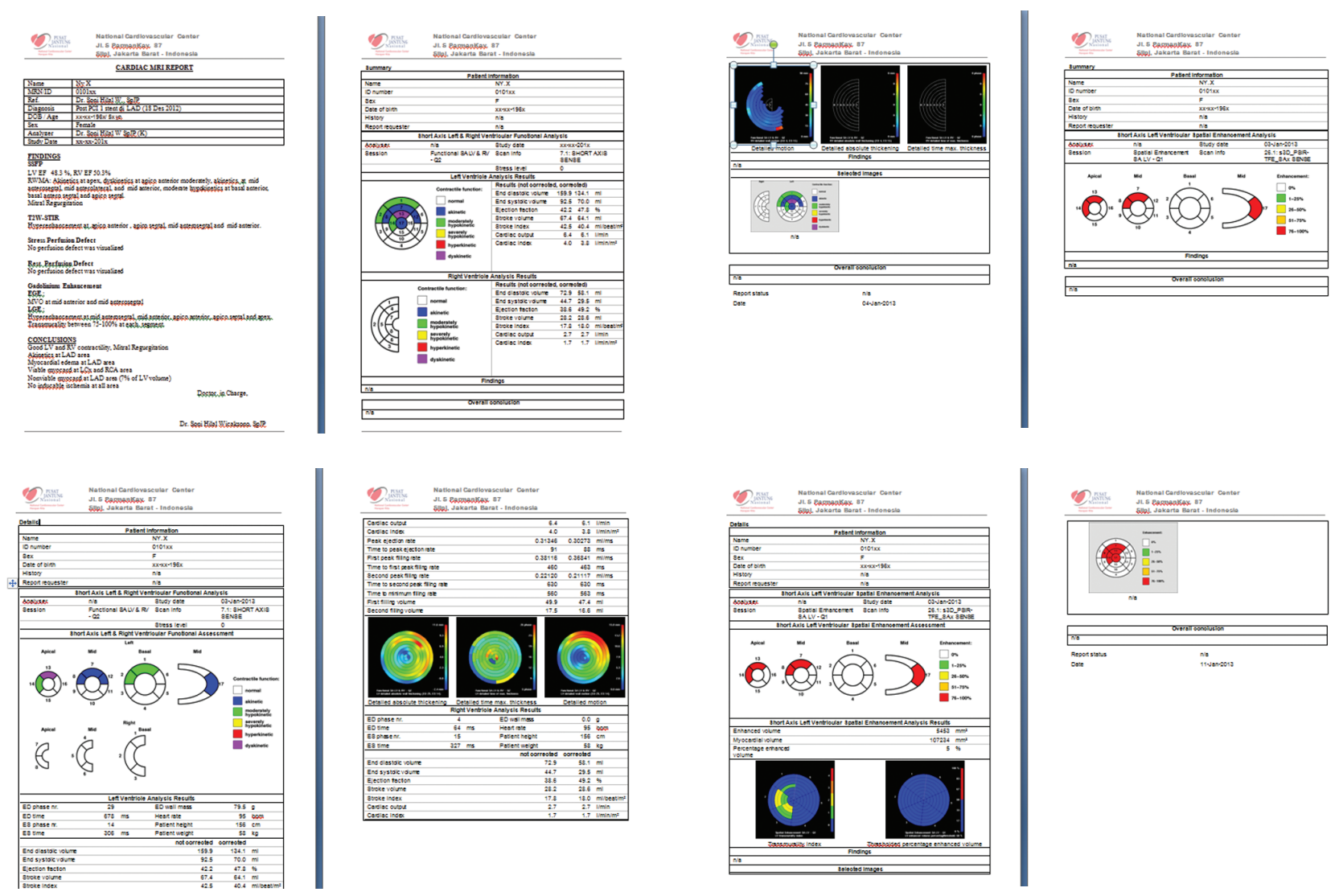

Gambar 11. Contoh pelaporan hasil MRI kardiak Rumah Sakit Pusat Jantung Nasional Harapan Kita.

3097-137.

2. Kwong RY. Cardiovascular Magnetic Resonance Imaging. In: Bonow RO, Mann DL, Zipes DP, Libby P. Braunwald's Heart Disease A Textbook of Cardiovascular Medicine. 9th Edition: Elsevier Saunders;2012:340-61.

3. Howarth AG, Friedrich MG. Imaging as an Endpoint in Ischemia Trials. Curr Cardiovasc Imaging Rep. 2011;4:90-97.

4. Lockie T, Nagel E, Redwood S, Plein S. Use of Cardivascular Magnetic Resonance Imaging in Acute Coronary Syndromes. Circulation. 2009; 119: 1671-81.

5. Lin EC, Klepac SR, Samett EJ, Pearlman JD, Coombs BD, Steiner RM, et al. Cardiac MRI, Technical Aspect Primer. In: http:/lemedicine.medscape.com/article/352250-overview; 2011.

6. Earls JP, Ho VB, Foo TK, Castillo E, Flamm SD. Cardiac MRI: Recent Progress and Future Challenges. Journal of Magmetic Resonance Imaging. 2002; 16: 111-27.

7. Marra MP, Lima JAC, Ilicto S. MRI in Acute Myocardial Infarc- tion. European Heart Journal. 2011; 32: 284-93.

8. Hundley WG, Bluemke DA, Finn JP, Flamm SD, Fogel MA, Friedriech MG, et al. 2010 ACCF/ACR/AHA/MASCI/SCMR Expert Consensus Document on Cardiovascular Magnetic Resonance: A Report on the American College of Cardiology Foundation Task Force on Expert Consensus Documents. Journal of the American College of Cardiology. 2010; 55(23): 2614-62.

9. Stuckley, DJ, Carr CA, Meader SJ, Tyler DJ, Cole MA, Clarke K. First-Pass Perfusion CMR Two Days After Infarction Predicts Severity of Functional Impairmant Six Weekes Later in the Rat Heart. Journal of Cardiovascular Magnetic Resonance. 2011; $13: 38$.

10. Kim RJ, Wu E, Rafael A, Chen EL, Parker MA, Simonetti O, et al. The Use of Contrast-Enhanced Magnetic Resonance Imaging to Identify Reversible Myocardial Dysfunction. N Engl J Med. 2000; 343:1445-53. 